\title{
THERMIONIC EMISSION FROM NEGATIVELY CHARGED METCARS: THE EXCEPTIONAL BEHAVIOUR OF $\mathrm{TI}_{13} \mathrm{C}_{22}{ }^{*}$
}

\author{
N. BLESSING, S. BURKART, D. KREISLE, AND G. GANTEFÖR \\ Fakultät für Physik, Universität Konstanz, 78457 Konstanz, Germany
}

We present a study of thermionic electron emission from negatively charged metalcarbon clusters excited by photoabsorption. Thermionic emission (TE) of electrons from hot surfaces [1] and clusters [2-7] competes with the evaporation of atoms [811] (or larger fragments), which is also a major cooling mechanism. For clusters, TE signal is observed only if the minimum energy necessary for fragmentation ( $\left.E_{\text {frag }}\right)$ is higher than the ionization potential or, in case of negatively charged clusters, the electron affinity $[12,13]$. Otherwise, the clusters primarily cool by evaporation, and, in general, $\mathrm{TE}$ is found for highly stable neutral clusters like $\mathrm{C}_{60}$ [4-6]. For negatively charged clusters, TE is more common, because the electron affinities are considerably lower than the ionization potentials of the neutrals and in many cases emission of electrons needs less energy than evaporation of atoms [13].

Recently, Castleman and coworkers discovered a new class of highly stable cage-like clusters similar to the fullerenes: the metallocarbohedrenes ("metcars") $[14,15]$. The smallest metcar consists of 8 metal atoms (e.g., Ti, $\mathrm{Zr}, \mathrm{Nb}$ ) and 12 carbon atoms and its geometric structure resembles that of the smallest possible fulleren $\mathrm{C}_{20}$. Larger metcars are assumed to be multi-cages consisting of several $\mathrm{Ti}_{8} \mathrm{C}_{12}$ units [16]. The bonding between the units is achieved by sharing parts of the walls of the cages the double-cage e.g. having the stochiometry $\mathrm{Ti}_{13} \mathrm{C}_{22}$.

Photoionization of single-cage metcars like $\mathrm{Ti}_{8} \mathrm{C}_{12}, \mathrm{~V}_{8} \mathrm{C}_{12}$ and $\mathrm{Nb}_{8} \mathrm{C}_{12}$ yields a large fraction of delayed ions [17-19], which is attributed to TE analogous to the case of $\mathrm{C}_{60}$. The strong TE signal detected is explained by the relatively low IPs of these clusters (about $4 \mathrm{eV}$ ) compared to the high stability (about $9 \mathrm{eV}$ dissociation threshold). For the $\mathrm{Ti}_{n} \mathrm{C}_{\mathrm{m}}$ system, the only cluster observed to undergo delayed ionization is $\mathrm{Ti}_{8} \mathrm{C}_{12}$, emphasizing the "supermagic" character of the single-cage metcar.

In this paper, we study the $\mathrm{TE}$ from negatively-charged $\mathrm{Ti}_{n} \mathrm{C}_{\mathrm{m}}{ }^{-}$metcars with the emphasis on TE from larger metcars like, e.g., the supposed double-cage metcar $\mathrm{Ti}_{13} \mathrm{C}_{22}{ }^{\circ}$. In contrast to the findings for the neutral $\mathrm{Ti}_{n} \mathrm{C}_{\mathrm{m}}$ clusters, we find a strong $\mathrm{TE}$ signal for all clusters in the size range around $\mathrm{Ti}_{8} \mathrm{C}_{12}{ }^{-}$, which is due to the low electron affinities of these clusters. However, for the negatively-charged $\mathrm{Ti}_{13} \mathrm{C}_{22}$. metcar we find a similar unique behavior as that known for the neutral single-cage [17,19]: only the $\mathrm{Ti}_{13} \mathrm{C}_{22}{ }^{-}$exhibits a $\mathrm{TE}$ signal in this size range. Accordingly, it must have a unique high stability compared to its neighbors with slightly different stochiometry like, i.e., $\mathrm{Ti}_{13} \mathrm{C}_{21}{ }^{-}$and $\mathrm{Ti}_{13} \mathrm{C}_{23}$. The electron affinities of these clusters are in the range between $1.8 \mathrm{eV}-2.5 \mathrm{eV}$ and, except for $\mathrm{Ti}_{13} \mathrm{C}_{22}{ }^{-}, \mathrm{E}_{\text {frag }}$ of these 
clusters must be smaller than this value. This is rather surprising, since the binding energies per atom are estimated to be about $6 \mathrm{eV}[20,21]$ and each $\mathrm{Ti}-\mathrm{C}$ bond energy is around $2.7 \mathrm{eV}[22]$.

We studied the TE of $\mathrm{Ti}_{\mathrm{n}} \mathrm{C}_{\mathrm{m}}$ - cluster anions by photoelectron spectroscopy. The experimental set-up is described in detail elsewhere $[23,24]$. The cluster anions are generated directly using a PACIS (pulsed arc cluster ion source). Titanium is vaporized by a pulsed electric arc from an electrode manufactured of bare $\mathrm{Ti}$ and the metal plasma is flushed by a carrier gas (Helium) containing a small amount of $\mathrm{CH}_{4}$ into a waiting room [25]. Here, the plasma cools and metal-carbon clusters grow. At the exit of the waiting room a weak discharge leads to an annealing of the clusters, i.e., the clusters are heated up again, and during the slow cooling process they may assume their ground state geometry [26]. Finally, the carrier gas containing neutral and charged $\mathrm{Ti}_{n} \mathrm{C}_{\mathrm{m}}$ clusters expands through a nozzle into vacuum.

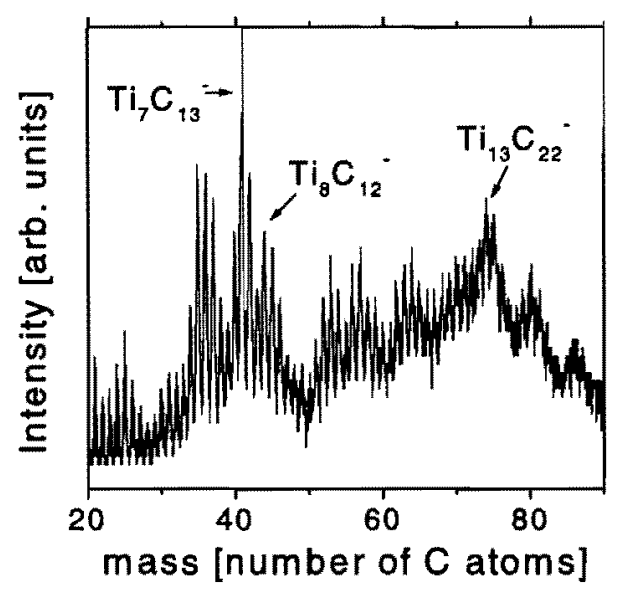

Figure 1 : Time-of-flight mass spectrum of $\mathrm{Ti}_{\mathrm{a}} \mathrm{C}_{\mathrm{m}}{ }^{-}$cluster anions generated directly by a pulsed arc cluster ion source $[23,24]$. The source has been operated using a waiting room [25] and an annealing discharge [26]. The spectrum is basically similar to one obtained with a laser vaporization source [27].

A typical time-of-flight mass spectrum of the annealed negatively charged metcars is shown in Fig. 1 and is similar to one obtained using a laser vaporization source [27]. The surprisingly low intensity of $\mathrm{Ti}_{8} \mathrm{C}_{12}{ }^{-}$can be explained by its exceptionally low electron affinity and is probably not related to its stability [21]. The mass spectrum is dominated by two maxima, one in the mass range around $\mathrm{Ti}_{7} \mathrm{C}_{13}{ }^{\circ}$ including $\mathrm{Ti}_{8} \mathrm{C}_{12}{ }^{-}$and the other around the mass of the supposed double cage cluster $\mathrm{Ti}_{13} \mathrm{C}_{22}$. For both maxima, not only are the peaks assigned to the "magic" number clusters $\mathrm{Ti}_{8} \mathrm{C}_{12}{ }^{-}$and $\mathrm{Ti}_{13} \mathrm{C}_{22}{ }^{-}$intense, but also the neighboring sizes exhibit sufficient intensity for photoelectron spectroscopy, allowing a systematic study of the TE signal from these clusters. 
A selected bunch of anions of defined size is irradiated by a UV laser pulse with a photon energy of $4.66 \mathrm{eV}$ with an intensity of about $50 \mathrm{~mJ} / \mathrm{cm}^{2}$. The kinetic energy of the emitted photoelectrons is measured using a "magnetic-bottle"-type time-of-flight electron spectrometer $[23,24]$. Electrons generated by thermionic emission are emitted with a delay with respect to the laser pulse and appear at longer time-offlight corresponding to a shift to lower kinetic energies $[12,13]$. However, the residence time of the anions in the source region of the electron spectrometer is relatively short compared to the typical electron time-of-flight and the shift can be neglected in a qualitative analysis. In the photoelectron spectra, TE can easily be identified by the appearance of an electron signal at low kinetic energies with an exponentially decreasing intensity with increasing kinetic energy. The decay constant depends on the vibrational temperature of the cluster, which can be estimated by dividing the energy of the absorbed photons by the number of the internal vibrational degrees of freedom $3 n-6$ ( $n$ : number of atoms). The low energy cut-off of the electron spectrometer is about $0.2 \mathrm{eV}$ and, accordingly, TE from clusters with more than about 10 atoms can only be observed if more than one photon is absorbed (at $\mathrm{hv}=4.66 \mathrm{eV}$ ). Otherwise, the TE signal is too low in regard to kinetic energies to be detected with our instrument [12].

After the absorption of one or several photons the excited cluster can dissipate its energy by two different mechanisms:

- direct emission of photoelectrons with a well defined kinetic energy.

- thermalization of the excitation energy into the internal vibrational modes resulting in a "superheated" cluster.

The "superheated" cluster cools by three competing channels:

1. thermionic emission of "hot" electrons with a kinetic energy distribution corresponding roughly to the vibrational temperature of the "superheated" cluster.

2. evaporation of atoms or larger fragments.

3. emission of photons (radiative cooling).

Radiative cooling can be neglected for the following reasons because of its much longer time scales. Direct emission of photoelectrons results in the appearance of more or less sharp features in the photoelectron spectra, which will be discussed elsewhere [28]. If the photon energy is thermalized, TE electrons will appear as a "background" signal at low kinetic energies, if the electron affinity (EA) of the cluster is lower than its $E_{\text {frag; }}$ i.e., TE electrons are observed for strongly bound elemental cluster anions like $\mathrm{C}_{\mathrm{n}}{ }^{-}$and $\mathrm{Pt}_{\mathrm{n}}{ }^{-}$clusters, but not for weakly bound systems like $\mathrm{Na}_{\mathrm{n}}{ }^{-}$and $\mathrm{Al}_{\mathrm{n}}{ }^{-}$[13]. If for a certain system both energies are in about the same range, it might happen that the stable "magic" clusters exhibit a strong TE signal and the others do not. However, such a strong variation of the TE signal with size has not been observed for negatively charged species yet. 
Fig. 2 and Fig. 3 display photoelectron spectra recorded from all mass peaks visible in Fig.1 which have sufficient intensity. In Fig.2, the spectra of the smaller $\mathrm{Ti}_{n} \mathrm{C}_{\mathrm{m}}$ clusters with masses around the single-cage metcar $\mathrm{Ti}_{8} \mathrm{C}_{12}{ }^{-}$are displayed. For each cluster a strong increase of electron signal at low kinetic energy is observed. These features peaking at zero kinetic energy are similar to ones observed in the spectra of, e.g., $W_{n}^{-}, C_{n}^{-}$(for $n>9$ ) and $\mathrm{Pt}_{n}^{-}$clusters and are assigned to TE [13]. The observation of the strong TE signal can be explained by the relatively low electron affinities of these clusters ranging from about $1 \mathrm{eV}$ for $\mathrm{Ti}_{8} \mathrm{C}_{12}{ }^{-}$up to about $1.7 \mathrm{eV}$ for $\mathrm{Ti}_{7} \mathrm{C}_{14}$. The relatively high intensity of these clusters in the mass spectrum (Fig.1) most likely corresponds to a high stability. The binding energy of a single Ti-C bond is of the order of $3 \mathrm{eV}$ [22] and these relatively stable clusters have most likely even higher thresholds for fragmentation. Accordingly, for these small metcars EA

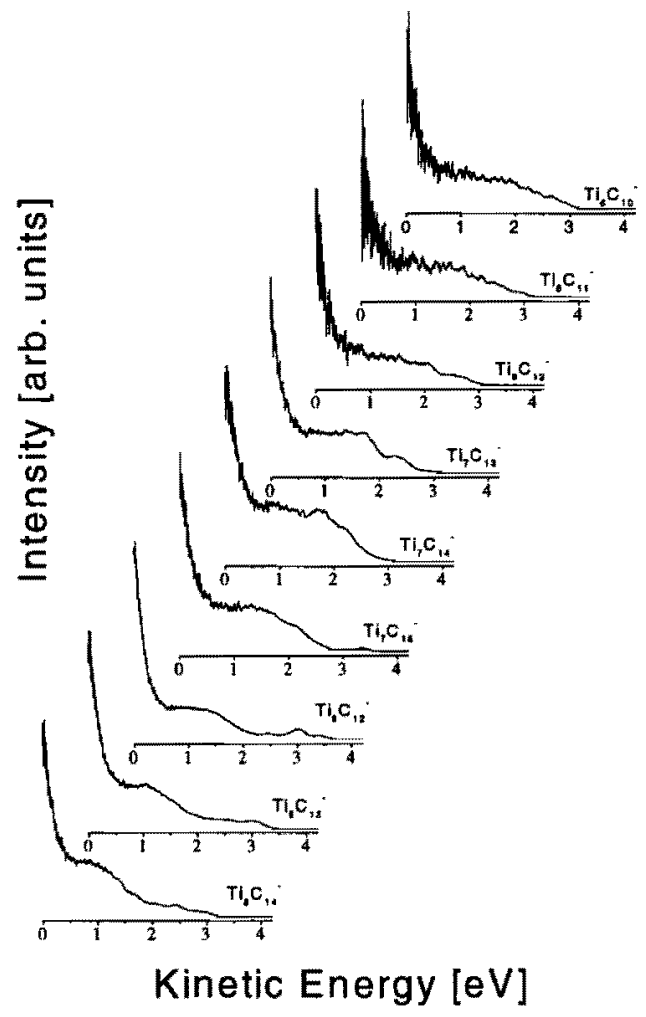

Figure 2 : Photoelectron spectra of $\mathrm{Ti}_{n} \mathrm{C}_{\mathrm{m}}{ }^{*}$ clusters with $\mathrm{n}=6-8$ and $\mathrm{m}=10-14$. The photon energy is $\mathrm{hv}=4.66 \mathrm{eV}$ and the laser intensity is about $50 \mathrm{~mJ} / \mathrm{cm}^{2}$. The features peaking at zero kinetic energy are assigmed to thermionic emission as a result of heating by the absorption of about $2-3$ photons. 
is smaller than $\mathrm{E}_{\text {frag }}$ and the hot clusters cool by TE. By comparing the estimated vibrational temperature of the "superheated" clusters with the number of vibrational degrees of freedom, we estimate that about two or three photons are absorbed by the anions.

In Fig.3 photoelectron spectra of the larger clusters $\mathrm{Ti}_{13} \mathrm{C}_{21}{ }^{\circ}, \mathrm{Ti}_{13} \mathrm{C}_{22}{ }^{*}$ and $\mathrm{Ti}_{13} \mathrm{C}_{23}$ are displayed. Only the spectrum of the "magic" cluster $\mathrm{Ti}_{13} \mathrm{C}_{22}$ " shows a narrow feature peaking at zero kinetic energy. We found no indication of a TE signal for any other cluster in the size range corresponding to the maximum in the mass spectrum centered at $\mathrm{Ti}_{13} \mathrm{C}_{22}{ }^{-}$(Fig.1). By comparison with a photoelectron spectrum obtained at a higher photon energy [27] the possibility that the feature at zero kinetic energy in the spectrum of $\mathrm{Ti}_{13} \mathrm{C}_{22}{ }^{-}$can be assigned to direct photoemission can be excluded. If this were the case, in the spectrum obtained at higher photon energy a peak located at a binding energy of $4.66 \mathrm{eV}$ should appear. However, no such peak has been observed [27]. The spectra displayed in Fig.3 have been recorded at the same laser intensity as the ones shown in Fig.2. Because of the larger number of vibrational degrees of freedom, the average kinetic energy of the TE electrons should be smaller for the larger clusters. Indeed, the peak at lowest kinetic energy in the spectrum of $\mathrm{Ti}_{13} \mathrm{C}_{22}$ is considerably narrower than the corresponding features in the spectra of the smaller clusters (Fig.2). We conclude that the peak at zero kinetic energy in the spectrum of $\mathrm{Ti}_{13} \mathrm{C}_{22}{ }^{-}$can be assigned to TE.

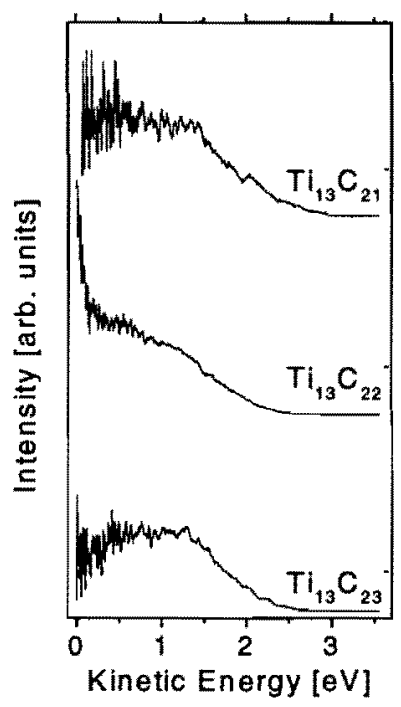

Figure 3: Photoelectron spectra of $\mathrm{Ti}_{13} \mathrm{C}_{21}, \mathrm{Ti}_{13} \mathrm{C}_{22}$ and $\mathrm{Ti}_{13} \mathrm{C}_{21}$ obtained at the same conditions as the spectra shown in Fig.2. 
With increasing cluster size the electron affinities generally increase. On the other hand, $E_{\text {frag }}$ might stay about constant for the evaporation of lowly coordinated atoms located at the surface of the cluster. Therefore, with increasing cluster size the cooling by evaporation might become the dominant decay channel except for the most stable "magic" clusters. This seems to be the case for the larger metcars studied here. According to the findings in the photoelectron spectra, for most $\mathrm{Ti}_{\mathrm{n}} \mathrm{C}_{\mathrm{m}}{ }^{-}$ clusters $\mathrm{E}_{\text {frag }}$ must be smaller than EA, which is about $2.5 \mathrm{eV}$. This is, however, somewhat surprising, because the binding energy per atom in a $\mathrm{Ti}_{\mathrm{n}} \mathrm{C}_{\mathrm{m}}$ - cluster is estimated to be about $6 \mathrm{eV}$ and even the energy of a single Ti-C bond is $3 \mathrm{eV} \mathrm{[22].}$ However, it is possible that evaporation of larger fragments like $C_{2}$ units occurs at lower $E_{\text {frag }}$.

In conclusion, we find that the negatively-charged "magic" cluster $\mathrm{Ti}_{13} \mathrm{C}_{22}$ shares one unique property with the neutral "supermagic" single-cage cluster $\mathrm{Ti}_{8} \mathrm{C}_{12}$ $[17,19]$ : in a certain size regime it is the only cluster which shows strong thermionic emission. However, from this finding we cannot deduce the geometric structure of $\mathrm{Ti}_{13} \mathrm{C}_{22}$, except for the fact that it must be a very stable one.

\section{References}

1. C. Herring and M. H. Nichols, Rev. Mod. Phys. 21, 185 (1949).

2. A. Amrein, R. Simpson, and P. Hackett, J. Chem.Phys. 94, 4663 (1991).

3. T. Leisner, K. Athanassenas, D. Kreisle, E. Recknagel, and O. Echt, J. Chem. Phys. 99, 9670 (1993).

4. E. E. B. Campbell, G. Ulmer, and I. V. Hertel, Phys. Rev. Lett. 67, 1986 (1991).

5. K. R. Lykke and P. Wurz, J. Phys. Chem. 96, 3191 (1992).

6. D. Ding, J. Huang, R. N.Compton, C. E. Klots, and R. E.Haufler, Phys. Rev. Lett. 73, 1084 (1994).

7. L. -S. Wang, J. Conceicao, C. Jin, and R. E. Smalley, Chem. Phys. Lett. 182, 5 (1991).

8. C. E. Klots, J. Chem. Phys. 83, 5854 (1985).

9. W. Begemann, K. H. Meiwes-Broer, and H. O. Lutz, Phys. Rev. Lett. 56, 2248 (1986).

10. L. A. Bloomfield, R. R. Freeman, and W. L. Brown, Phys. Rev. Lett. 54, 2246 (1985).

11. M. L. Alexander, M. A. Johnson, N. E. Levinger, and W. C. Lineberger; Phys. Rev. Lett. 57, 976 (1986).

12. H. Weidele, D. Kreisle, E. Recknagel, G. Schulze Icking-Konert, H. Handschuh, G. Ganteför, and W. Eberhardt, Chem. Phys. Lett. 237, 425 (1995).

13. G. Ganteför, W. Eberhardt, H. Weidele, D. Kreisle, and E. Recknagel, Phys. Rev. Lett. 77, 4524 (1996).

14. B. C. Guo, K. P. Kerns, and A. W. Castleman, Jr., Science 255, 1411 (1992). 
15. B. C. Guo, S. Wei, J. Purnell, S. Buzza, and A. W. Castleman, Jr., Science 256, 511 (1992).

16. S. Wei, B. C. Guo, J. Purnell, S. Buzza, and A. W. Castleman, Jr., Science 265, 818 (1992).

17. B. D. May, S. F. Cartier, and A. W. Castleman, Jr., Chem. Phys. Lett. 242, 265 (1995).

18. S. F. Cartier, B. D. May, and A. W. Castleman, Jr., J. Chem. Phys. 104, 3423 (1996).

19. S. E. Kooi and A. W. Castleman, Jr., J. Chem. Phys. 108, 8864 (1998).

20. A. Khan, Chem. Phys. Lett. 247, 447 (1995).

21. J. Munoz, M. -M. Rohmer, M. Benard, C. Bo, and J. -M. Poblet, J. Phys. Chem.A 103, 4762 (1999).

22. A. Khan, J. Phys. Chem. 99, 4923 (1995).

23. Chia-Yen Cha, G. Ganteför, and W. Eberhardt, Rev. Sci. Instrum. 63, 5661 (1992).

24. H. Handschuh, G. Ganteför, and W. Eberhardt, Rev. Sci. Instrum. 66, 3838 (1995).

25. B. C.Guo, S. Wei, Z. Chen, K. P. Kerns, J. Purnell, S. Buzza, and A. W. Castleman, J. Chem. Phys. 97, 5243 (1992).

26. H. Handschuh, G. Ganteför, B. Kessler, P. S. Bechthold, and W. Eberhardt, Phys. Rev. Lett. 74, 1095 (1995).

27. L, -S. Wang and H. Cheng, Phys. Rev. Lett. 78, 2983 (1997).

28. N. Blessing, S. Burkart, and G. Ganteför, to be published. 